\title{
Gescheiterte Memoria? - Anmerkungen zu den „Hausklöstern“ des hochmittelalterlichen Adels
}

\author{
Von JÜrgen Dendorfer
}

Im Jahr 1803 erwarben die Fürsten von Löwenstein-Wertheim durch den Reichsdeputationshauptschluss die Zisterze Bronnbach ${ }^{1}$. Nach Ansicht des Fürstenhauses entsprach dies einer historischen Logik: Sei doch die Abtei von ihren Vorfahren gegründet worden und somit geradezu eine Familienstiftung, was die Fürsten dem Kloster gegenüber besonders verpflichte ${ }^{2}$. Unbegründet war diese schon in der Frühen Neuzeit vertretene Ansicht in der Tat nicht: Seit der zweiten Hälfte des 14. Jahrhunderts übten die Wertheimer den Schutz über das Kloster aus, aus dieser Zeit haben sich die bekannten Gräber von im Kloster bestatteten Angehörigen der Familie erhalten ${ }^{3}$. Spuren gräflicher Nähe zum Kloster lassen sich bis in die Mitte des 12. Jahrhunderts zurückverfolgen - vom ersten Hinweis auf das Grab eines Familienmitglieds in Bronnbach um $1200^{4}$ bis zu Erwähnungen des Grafen Wolfram als

1 Zur Säkularisation Bronnbachs: Leonhard Scherg, Eine schöne Acquisition für das Fürstliche Haus Löwenstein ... Die Säkularisation der Zisterzienserabtei Bronnbach, in: Alte Klöster - Neue Herren. Die Säkularisation im deutschen Südwesten 1803. Aufsätze, 1. Teil: Vorgeschichte und Verlauf der Säkularisation, hg. von Hans Ulrich Rudolf unter redaktioneller Mitarbeit von Markus Blatt, Ostfildern 2003, S.609-620; Leonhard Scherg, Die Zisterzienserabtei Bronnbach 1802/1803 - Säkularisation und Auflösung, in: Wertheimer Jahrbuch 2002 (2003) S. 127-204.

${ }^{2}$ Leonhard Scherg, Die Zisterzienserabtei Bronnbach im Mittelalter. Studien zur Geschichte der Abtei von der Gründung bis zur Mitte des 14. Jahrhunderts (Mainfränkische Studien, Bd.14), Würzburg 1974, S.32f.; Ders., Die Zisterzienserabtei Bronnbach (wie Anm. 1) S. 170, mit der Ordnung des Fürsten Dominik Constantin für das Kloster vom 24. Februar 1803, in dem Bronnbach, als ... die von unseren Gottseligen Voreltern gestiftete Abtey ... bezeichnet wird.

3 Scherg, Bronnbach im Mittelalter (wie Anm. 2) S. 44-47; Harald Drös, Kloster Bronnbach als Begräbnis- und Memorialstätte, in: Kloster Bronnbach 1153-1803. 650 Jahre Zisterzienser im Taubertal, hg. von Peter Müller, Wertheim 2003, S. 103-120, zu den Wertheimer Grabmälern des 14. Jahrhunderts, S. 109f.; zum Widerspruch zwischen den Bestimmungen des Zisterzienserordens gegen die Bestattung von Laienadeligen und der Bestattungspraxis vgl. Maria Magdalena Rückert, Bestattungsverbot versus Stiftergrab - Südwestdeutsche Zisterzienserklöster als Begräbnisstätten, in: Studien und Mitteilungen zur Geschichte des Benediktinerordens 116 (2005) S. 89-105.

${ }^{4}$ Peter Rückert, Adelige Herrschaft und Repräsentation im hohen Mittelalter. Literatur 
Förderer und Wohltäter in einer der frühesten Urkunden aus dem Jahr $1159^{5}$. War Bronnbach somit ein „Hauskloster" der Grafen von Wertheim?

Vieles könnte dafür sprechen: Graf Wolfram, sein Bruder und seine Schwester schenkten in den ersten Jahrzehnten an das Kloster. Die Zisterze im unteren Taubertal diente als Grablege, und die Grafen von Wertheim übten später den Schutz über das Kloster aus. Über die Jahrhunderte hinweg zeigen sich somit Elemente einer vielfach verwendeten, impliziten Hausklosterdefinition. Nimmt man diese jedoch genauer in den Blick, dann stellen sich Zweifel ein: Maßgebliche Gründer des Klosters waren die Grafen von Wertheim sicher nicht, denn die frühesten Urkunden lassen ein durch mehrfache Brüche gekennzeichnetes Gründungsgeschehen erkennen. Durch Studien von Leonhard Scherg ${ }^{6}$, Hermann Ehmer ${ }^{7}$, Peter und Maria Magdalena Rückert ${ }^{8}$ sowie Dietlinde Schmitt-Vollmer ${ }^{9}$ wissen wir, dass das Kloster eine Gruppe von verwandtschaftlich verbundenen Edelfreien, an der Spitze Beringer von Gamburg, in enger Abstimmung mit dem Mainzer Erzbischof Arnold von Selenhofen ins Werk setzte. Die Grafen von Wertheim traten zwar früh

und Architektur im Umfeld der Grafen von Wertheim und der Herren von Gamburg, in: Wirtschaft - Gesellschaft - Mentalitäten im Mittelalter. Festschrift zum 75. Geburtstag von Rolf Sprandel, hg. von Hans-Peter Baum/Rainer Leng/Joachim Schneider (Beiträge zur Wirtschafts- und Sozialgeschichte, Bd. 107), Stuttgart 2006, S. 289-306, hier S. 296.

${ }^{5}$ In der Urkunde Papst Hadrians IV. für Bronnbach: Germania Pontificia III,3, bearb. von Albert Brackmann, Berlin 1935, Nr.2, S.201; Druck: Joseph von Aschbach, Geschichte der Grafen von Wertheim von den ältesten Zeiten bis zu ihrem Erlöschen im Mannesstamme im Jahre 1556, 2. Teil: Wertheimisches Urkundenbuch, Frankfurt a. Main 1843, Nr.5, S.6f, hier S. 7 ... Ex dono Comitis Wolframi de Wertheim villam Lullenseit et Fallebrunne.

${ }^{6}$ Scherg, Bronnbach im Mittelalter (wie Anm. 2); Ders., Zur Geschichte der Zisterzienserabtei Bronnbach, in: Kloster Bronnbach (wie Anm. 3) S. 11-35, hier S. 16-20.

7 Hermann Ehmer, Geschichte der Grafschaft Wertheim, Wertheim 1989, hier S. 29-34.

8 Peter Rückert, Zu den Anfängen der Gamburg und ihren ersten Besitzern, in: Wertheimer Jahrbuch 1994, S. 9-22; Ders., Adelige Herrschaft (wie Anm. 4); Ders., Die Edelfreien von Lauda, Zimmern und Gamburg, in: Hochmittelalterliche Adelsfamilien in Altbayern, Franken und Schwaben, hg. von Ferdinand Kramer/Wilhelm Störmer (Studien zur bayerischen Verfassungs- und Sozialgeschichte, Bd. 20), München 2005, S. 591-642, hier S.608610, 620-630; Maria Magdalena Rückert, Die Anfänge der Klöster Schöntal und Bronnbach und ihr Verhältnis zur Mutterabtei Maulbronn, in: Anfänge der Zisterzienser in Südwestdeutschland, hg. von Peter Rückert (Oberrheinische Studien, Bd. I6), Stuttgart 1999, S. 101-125; Dies., Zum Rücktritt des ersten Bronnbacher Abtes Reinhard im Kirchenstreit zwischen Kaiser Friedrich Barbarossa und Papst Alexander III., in: Wertheimer Jahrbuch 1996, S. 9-24.

9 Dietlinde Schmitt-Vollmer, Bronnbach. Ein Grablegeprojekt im 12. Jahrhundert. Zur Baugeschichte der Zisterzienserkirche (Forschungen und Berichte der Bau- und Kunstdenkmalpflege in Baden-Württemberg, Bd.12), Stuttgart 2007; stärker ordensinterne Einflüsse der Zisterzienser auf die Baugestaltung stellt dagegen fest: Katinka KRUG, Kloster Bronnbach. Die Baugeschichte der Kirche und Klausur des Zisterzienserklosters (Forschungen und Berichte der Bau- und Kunstdenkmalpflege Baden-Württemberg, Bd. 15), Stuttgart 2012. 
hinzu, die Initiative lag aber nicht bei ihnen. Die ambitionierteste Memorialstrategie verband wohl Erzbischof Arnold mit dem Bau des Klosters ${ }^{10}$.

Diese Vielschichtigkeit der Gründung Bronnbachs wird überdeckt, wenn aus der Kenntnis späterer Entwicklungen die Anfänge des Klosters zu eng mit den Grafen von Wertheim verbunden werden. Zumindest für die ersten Jahrzehnte der Geschichte des Klosters verdunkelt die Einordnung als „Hauskloster“ mehr als sie erhellt. Sie verstellt den Blick auf zeitgenössische Motive für die Gründung, auf Memorialstrategien der Beteiligten sowie auf das Verhältnis des Klosters zu anderen Adeligen. Zum eigentlichen „Hauskloster" wurde Bronnbach zudem erst in der zweiten Hälfte des 14. Jahrhunderts, als mehrere Angehörige der Stifterfamilie dort ihr Grab fanden und die Grafen den Schutz des Klosters ausübten. Nur wenige Jahrzehnte nach diesem historischen Moment verlegten die Wertheimer aber ihre Grablege. Einer Tendenz der Zeit folgend nutzten sie einen öffentlichkeitswirksameren und repräsentativeren Ort: die neu errichtete Stiftskirche von Wertheim $^{11}$. Dieser Befund relativiert in diesem wie in anderen Fällen die „herausragende Bedeutung einer generationenübergreifenden Grablege“, wie Karl-Heinz Spieß zu Recht angemerkt hat ${ }^{12}$.

Die Diskussion um die Charakteristika eines Hausklosters sollte exemplarisch an der Zisterze Bronnbach dargelegt werden. Auch wenn die Zisterzienser anfänglich versuchten, durch ein Bestattungsverbot und neue Formen des kumulativen Gedenkens die Stiftermemoria in ihren Klöstern zu beschränken, dürften sich die Erwartungen der Stifter von Zisterzen kaum von derjenigen von benediktinischen Klöstern unterschieden haben. Jenseits der Beschlüsse zisterziensischer Generalkapitel bildete sich eine Memorialpraxis heraus, die Zisterzen in der zweiten Hälfte des 12. Jahrhundert sowohl für den hohen Adel als auch für Ministeriale und Edelfreie attraktiv erscheinen ließ ${ }^{13}$. Ungeachtet dieser Einschränkungen lässt sich

${ }^{10}$ Vgl. zu Erzbischof Arnold von Selenhofen den Beitrag von Stefan Weinfurter in diesem Band. Schmitt-Vollmer (wie Anm. 9) sieht in der Kirche von Bronnbach eine von Arnold geförderte und geplante Grablege, die 1180/1190 abgeschlossen sei und in ihren Formen einen gesteigerten repräsentativen Anspruch „als Grabkirche des ,Märtyrer-Erzbischofs"“ erhebe (S. 191).

${ }^{11}$ Hermann Ehmer, Die Stifter der Wertheimer Stiftskirche, in: Wertheimer Jahrbuch 1984/1985, S. 13-30; Judith Wipfler, Der Chor der Wertheimer Stiftskirche als herrschaftliche Grablege. Die Epitaphien der Regenten bis ins frühe 17. Jahrhundert, in: Wertheimer Jahrbuch 1996, S. 87-178, hier besonders S. 90-105 zum Grab Graf Johanns I. (†1407); KarlHeinz SpIEss, Liturgische Memoria und Herrschaftsrepräsentation im nichtfürstlichen Adel des Spätmittelalters, in: Adelige und bürgerliche Erinnerungskulturen des Spätmittelalters und der Frühen Neuzeit, hg. von Werner Rösener (Formen der Erinnerung, Bd. 8), Göttingen 2000, S. 97-123, hier S. $107 \mathrm{f}$.

12 Spiess, Liturgische Memoria (wie Anm. 11) S. 122.

13 Vgl. dazu M.M. RückeRT, Bestattungsverbot (wie Anm. 3); ferner zu den Bestimmungen des Ordens im 12. Jahrhundert und den steinernen Zeugnissen der Sepulkralkultur: Eberhard J. Niкiтsch, Zur Sepulkralkultur mittelrheinischer Zisterzienserklöster, in: Epigraphik 1988. Fachtagung für Mittelalterliche und Neuzeitliche Epigraphik. Graz 10.-14. 
das, was an Bronnbach verdeutlicht werden sollte, bei zahllosen Klostergründungen des 11. und 12. Jahrhunderts beobachten: Zum „Hauskloster“ eines Adelsgeschlechts wird ein Kloster häufig erst im Nachhinein. Nicht selten verstellt eine derartige Einordnung den Blick auf vielfältigere Anfänge und Traditionsbrüche. Im schlimmsten Fall sitzt eine solche Deutung nachträglichen historiographischen Sinnfindungen und Stilisierungen aus dem Konvent selbst oder zumindest von interessierter Seite, wie in Bronnbach, auf.

Spricht man über das Verhältnis des hochmittelalterlichen Adels zu Klöstern, dann prägt allerdings die Rede von den „Hausklöstern“ bis heute den Blick. Ihr liegt ein Konzept zugrunde, das nie sonderlich ausgearbeitet wurde und das von einem impliziten Vorverständnis ausgeht. Im Folgenden soll an südwestdeutschen Beispielen einem Fragenkreis um dieses Problem nachgegangen werden. Welche Definitionen bietet die Forschung für das „Hauskloster“ (1.), wie weit tragen diese noch (2.) und welche Motive und Funktionen adeliger Klostergründungen des 11. und 12. Jahrhunderts lassen sich erkennen (3.).

\section{Das Hauskloster zwischen adeligem Individuum, Familie und Geschlecht}

Beginnen wir mit einer vielzitierten Definition, die Wilhelm Störmer im Jahr 1980 vorschlug. Danach ergebe sich das „Wesen“ wittelsbachischer Hausklöster daraus, dass sie erstens von den Wittelsbachern gegründet wurden oder diese zumindest eine „entscheidende Mitteilhabe“ an der Stiftung hatten. Zweitens wiesen diese Klöster eine Stiftergrablege in der Kirche oder im Kloster auf, die sich zur Familiengrablege erweitern konnte. In ihnen wurde drittens das Gebet und die Messe für die Stifter verrichtet und viertens die Vogtei über das Kloster „von der Familie bzw. vom herrschenden Repräsentanten nicht mehr aus der Hand gege-

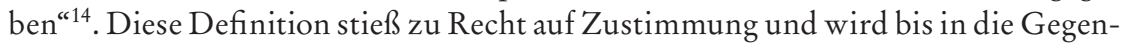
wart gerne zitiert, nicht zuletzt weil ähnlich klärende Vorstöße lange Zeit fehlten.

Doch auch bei den von Störmer herangezogenen Beispielen zeigt sich bei näherem Zusehen, was an Kloster Bronnbach verdeutlicht werden sollte. Die Gründungsumstände dieser wittelsbachischen Hausklöster sind selten so eindeutig, dass das Verhältnis einzelner Gründer aus verschiedenen wittelsbachischen Linien zu

Mai 1988. Referate und Round-Table Gespräche, hg. von Walter KocH (Österreichische Akademie der Wissenschaften, Philosophisch-historische Klasse, Denkschriften, Bd. 213), Wien 1990, S. 179-194, hier vor allem S. 181-185.

14 Wilhelm Störmer, Die Hausklöster der Wittelsbacher, in: Wittelsbach und Bayern, Bd. I/1, München 1980, hg. von Hubert Glaser, München 1980, S. 139-150, hier S. 148; vgl. den Aufsatz wieder in: STÖrmer, Mittelalterliche Klöster und Stifte in Bayern und Franken, hg. von Elisabeth Lukas-Götz/Ferdinand Kramer/Andreas Otto Weber, St. Ottilien 2008, S. 103-127, hier S. 125 f. 
den Klöstern von Anfang an all diese Kriterien umfasste. Nachträglich betrachtet, stellen sich die genannten Elemente zwar ein, die Intentionen der Stifter oder das Verhältnis der Wohltäter und Förderer zu den Klöstern in den ersten Jahrzehnten mitunter sogar im ersten Jahrhundert erfasst die Kategorisierung als „Hauskloster" allerdings nicht angemessen.

Scheyern etwa darf nur dann zu Recht als das „Hauskloster“ der „Wittelsbacher“ gelten, wenn man sich bewusst ist, dass es erst um 1200, mehr als ein Jahrhundert nach dem Beginn des Gründungsprozesses, zum hervorgehobenen Memorial- und Erinnerungsort der nunmehrigen bayerischen Herzogsfamilie wurde ${ }^{15}$. Das Kloster gründeten nicht die „Wittelsbacher“, vielmehr beabsichtigte 1077 die Witwe Haziga für das Seelenheil ihres verstorbenen zweiten Gatten, Graf Otto von Scheyern, zu sorgen ${ }^{16}$. Nach mehrfachen Versuchen einer örtlichen Verstetigung kamen die Mönche von Bayrischzell, nach Fischbachau und dann auf dem Petersberg (bei Eisenhofen) 1119 in der namensgebenden Burg der Grafen von Scheyern zur Ruhe $^{17}$. Zu dieser Zeit war Gräfin Haziga längst verstorben, an ihre Stelle traten ihre Söhne, die den Stifterwillen der Mutter erfüllten. Warum aber gaben die Grafen von Scheyern 1119 ihren Stammsitz auf und verlegten ein Kloster in diesen? In vergleichbaren Fällen deutet dies auf das Aussterben eines Adelsgeschlechts oder zumindest auf tiefgreifende Umstrukturierungen seines Besitz- und Herrschaftsgefüges hin ${ }^{18}$. In der Tat stellen diese Jahre eine wichtige Etappe im Aufstieg der Grafen von Scheyern dar ${ }^{19}$, denn um diese Zeit übertrug Kaiser Heinrich V. an einen Enkel der Gräfin Haziga, Otto, die bayerische Pfalzgrafschaft ${ }^{20}$. Die Hand-

15 StÖrmer, Die Hausklöster (wie Anm. 14) S. 140-142; Ferdinand Kramer, Geschichtsschreibung zwischen Rückbesinnung auf Hirsauer Tradition und adeligem Machtanspruch. Eine quellenkritische Studie zur Scheyerner Chronik, in: Zeitschrift für bayerische Landesgeschichte 57 (1994) S. 351-381.

16 Gabriele Schlütter-Schindler, Die Frauen der Herzöge. Schenkungen und Stiftungen der bayerischen Herzoginnen an Klöster und Stifte des Herzogtums und der Pfalzgrafschaft von 1077 bis 1355 (Zeitschrift für bayerische Landesgeschichte, Beiheft, Reihe B, Bd. 16), München 1999, S.3-11.

17 Gut dokumentiert sind diese Vorgänge in der frühen urkundlichen Überlieferung zum Kloster: Die Traditionen des Klosters Scheyern, bearb. von Michael Stephan (Quellen und Erörterungen zur bayerischen Geschichte, NF 36,1), München 1986; hier Nr.1-5, S.3-19; Die Urkunden und die ältesten Urbare des Klosters Scheyern, bearb. von Dems. (Quellen und Erörterungen zur bayerischen Geschichte, NF 36,2), München 1988, hier Nr.1-5, S. 3-20.

${ }^{18}$ Vgl. etwa als Übersicht Gerhard Streich, Adel, Burg und Klostergründung. Motive und Familienkonstellationen zwischen „Haus“- und „Gedächtnisklöstern“ im hohen Mittelalter, in: Vielfalt und Aktualität des Mittelalters. Festschrift für Wolfgang Petke zum 65. Geburtstag, hg. von Sabine Arend u. a., Bielefeld 2006, S. 39-71, hier S. 50 f.

19 Zur Einordnung des Ereignisses: Stefan Weinfurter, Der Aufstieg der Wittelsbacher, in: Gelebte Ordnung - Gedachte Ordnung. Ausgewählte Beiträge zu König, Kirche und Reich. Aus Anlaß des 60. Geburtstages, hg. von Helmuth Kluger/Hubertus Seibert/Werner Bомм, Ostfildern 2005, S. 135-157, hier S. 143 f.

${ }^{20}$ Hubertus Seibert, Die entstehende „territoriale Ordnung“ am Beispiel Bayerns, in: 
lungsräume des neuen Pfalzgrafen von Bayern, der sich nun nicht mehr nach Scheyern, sondern nach „Wittelsbach“ benannte, erweiterten sich um den bayerischen Nordgau, die heutige Oberpfalz, und ins Aichacher Land, wo die Burg Wittelsbach lag. Diese veränderten räumlichen Schwerpunkte spiegeln sich auch in neuen Klostergründungen. Während in Scheyern in der ersten Hälfte des 12. Jahrhunderts offenbar nur die Familie der Gräfin Haziga - sie, ihr Gemahl und ihre Söhne - begraben wurde, ließ sich der erste Pfalzgraf gemeinsam mit seiner Frau im Kloster Ensdorf in der Oberpfalz bestatten, das er aus dem Erbe seines Schwiegervaters Friedrich von Pettendorf-Lengenfeld-Hopfenohe errichtete ${ }^{21}$. Um dieselbe Zeit gründete dieser Pfalzgraf Otto I. auch das Augustinerchorherrenstift Indersdorf im Dachauer Hinterland ${ }^{22}$. Erst der Sohn Pfalzgraf Ottos I., Pfalzgraf Otto II., der unermüdliche Helfer Friedrich Barbarossas, den dieser 1180 zum Herzog von Bayern erhob, ließ sich wieder in Scheyern bestatten. Unter seinem Sohn Ludwig entstand mit der Fürstenkapelle ein Memorialort der wittelsbachischen Herzogsfamilie in Scheyern. Bis um 1180 aber dominierten in Scheyern die Grafen von Dachau, die im Kloster über zwei Generationen ihre Grablege hatten und sich dort als Förderer im Traditionsbuch nachweisen lassen ${ }^{23}$.

Bis etwa 1180 könnte man Scheyern somit als „Hauskloster“ der Grafen/Herzöge von Dachau bezeichnen, die nur genealogisch aus rückblickender Betrachtung als „Wittelsbacher“ anzusprechen sind. Wie in andere Herrschaftsrechte der Dachauer, welche die Pfalzgrafen von Wittelsbach durch Kauf erwarben, rückten sie auch in deren Vogteirechte über Scheyern ein. Die Rückkehr der pfalzgräflichen

Stauferreich im Wandel. Ordnungsvorstellungen und Politik in der Zeit Friedrich Barbarossas (Mittelalter-Forschungen, Bd. 9), Stuttgart 2002, S. 253-287, hier S. 262 f.; zur Zeitstellung der Übertragung des Pfalzgrafenamts: Christof Paulus, Das Pfalzgrafenamt in Bayern im Frühen und Hohen Mittelalter (Studien zur bayerischen Verfassungs- und Sozialgeschichte, Bd.25), München 2007, S. 282-290.

${ }^{21} \mathrm{Zu}$ Ensdorf: Störmer, Die Hausklöster (wie Anm. 14) S. 142f.; zu Friedrich von Pettendorf-Hopfenohe-Lengenfeld: Alois Sснміd, Die Herren von Pettendorf-LengenfeldHopfenohe, in: Hochmittelalterliche Adelsfamilien in Altbayern, Franken und Schwaben, hg. von Ferdinand Kramer/Wilhelm StÖRmer (Studien zur bayerischen Verfassungsund Sozialgeschichte, Bd. 20), München 2005, S. 319-340, zur geplanten Gründung Ensdorfs durch Friedrich von Pettendorf-Lengenfeld-Hopfenohe hier S. 329 f.; zu Ensdorf als Grablege Pfalzgraf Ottos I. und seiner Gattin Heilika: Claudia List, Die mittelalterlichen Grablegen der Wittelsbacher in Altbayern: Scheyern - Ensdorf - Fürstenfeld - München Liebfrauendom - Landshut-Seligenthal, in: Wittelsbach und Bayern, Bd.I/1 (wie Anm.14) S. 521-540, hier S. 525-527.

22 Vgl. StÖrmer, Die Hausklöster (wie Anm. 14) S. 144 f., der auf die Angaben zur Bestattung im Stift aus Morharts Klostergeschichte des 18. Jahrhunderts verweist, die aber in Widerspruch zu Ensdorfer Nachrichten stehen.

${ }_{23}$ Pankraz Fried, Die Landgerichte Dachau und Kranzberg (Historischer Atlas von Bayern, I: Teil Altbayern, Bd.11-12), München 1958, S. 5-10; Die Traditionen des Klosters Scheyern (wie Anm. 17) Nr. 21, S. 28-30; Nr. 22, S. 29f.; Nr. 50, S. 52 f. (Bestattung Herzog Konrads III. in Dachau); Nr.51, S.54; Schenkungen von Ministerialen der Grafen von Dachau: ebd., Nr. 40, 41, 42, 43, 44. 
Wittelsbacher nach 1180 lässt sich also als Teil der bewussten Inbesitznahme der Hinterlassenschaft der Grafen von Dachau deuten. Die ersten beiden Kriterien für ein Hauskloster, die Wilhelm Störmer benannt hat - Gründung durch die Familie und Stiftergrablege -, treffen somit zwar auf Scheyern zu, sie sind jedoch für das erste Jahrhundert der Klostergeschichte nur im Rückblick, aus der Gewissheit eines wittelsbachischen Familienzusammenhangs und der Tatsache des um 1200 geschaffenen Haus- und Memorialklosters der Herzogsfamilie anzuwenden.

Bemerkenswerter und für den Historiker erhellender sind die Brüche in der Gründungsgeschichte und das Phänomen der wechselnden Grablegen der Stifterfamilie der Grafen von Scheyern und ihrer Nachfahren bis zur „Rückkehr“ Herzog Ottos I. am Ende des 12. Jahrhunderts. Aus dieser Perspektive schärft sich auch der Blick für den erstaunlichen und ungewöhnlichen Versuch der wittelsbachischen Herzogsfamilie, am Ende des 12. Jahrhunderts wieder an die Anfänge der Grafen von Scheyern anzuknüpfen. Im Kloster selbst schrieb man die Geschichte der Stifter und Wohltäter des Klosters in der um 1209/1210 entstandenen Chronik Konrads von Scheyern nieder ${ }^{24}$. Wie Ferdinand Kramer herausarbeiten konnte, versuchte der Chronist aus einer „besitz- und rechtssichernden Intention“ heraus, „eine familiäre Kontinuität bei den Stiftern des Klosters herzustellen“25. Wir verdanken ihm gleichsam als Nebenfrucht Informationen über die Geschichte der frühen „Wittelsbacher“ - der Grafen von Scheyern, der Grafen und Herzöge von Dachau und der Pfalzgrafen -, da er die miteinander verwandten adligen Förderer des Klosters benannte und versuchte, deren familiäre Verbindungen untereinander und mit der wittelsbachischen Herzogsfamilie am Beginn des 13. Jahrhunderts herzustellen. Auf diese Weise schuf der Chronist das genealogische Bewusstsein einer Zusammengehörigkeit der Wittelsbacher über verschiedene Familienzweige hinaus. Auch das vierte Kriterium der Hausklosterdefinition, die Vogtei in den Händen der Stifterfamilie, trifft auf Scheyern $\mathrm{zu}^{26}$; allerdings war das Verhältnis zwischen Kloster und Stifterfamilie auch bis zum Zerreißen gespannt ${ }^{27}$.

Selbst im prominenten, scheinbar so eindeutigen Fall von Scheyern sollte man somit unterscheiden zwischen den Motiven der Gründer eines Klosters und dem, was sich aus nachträglicher, historiographischer Betrachtung an dauerhaften und stabilen Beziehungen einer Adelsfamilie zu einem Kloster rekonstruieren lässt. „Hausklöster“ im Sinne dieser Definition sind häufig erst im Nachhinein zu greifen. Solche Funktionszuschreibungen ex post sind somit deutlich zu unterscheiden

24 Chuonradi Schirensis Chronicon, hg. von Philipp Jaffé, in: MGH SS XVII, Hannover 1861, S. 615-641; Übersetzung: Pankraz Fried, Die Chronik des Abtes Konrad von Scheyern (1206-1225) über die Gründung des Klosters Scheyern und die Anfänge des Hauses Wittelsbach, Weißenhorn 1980, S. 19-36.

25 Kramer (wie Anm. 15) S. 380.

26 Zur Vogtei: Stephan, Einleitung, in: Die Traditionen des Klosters Scheyern (wie Anm. 17) Nr. S. 71*-93\%; Kramer (wie Anm. 15) S. 365-386.

27 Kramer (wie Anm. 15) S. 366 f. 
von den Intentionen der Akteure, die eine implizite Hausklosterdefinition zu erklären suggeriert.

Bedeutung kommt den genannten Elementen der Hausklosterdefinition - Gründung durch eine „Familie“, Grablege, Memoria für diese in Liturgie und Gebet und Ausübung der Vogtei in der Stifterfamilie - dadurch zu, dass diese in der Forschung explizit in Bezug gesetzt werden zum Strukturwandel des Adels vom Frühzum Hochmittelalter ${ }^{28}$. Nach Karl Schmid kam „Hausklöstern“ „im eigentlichen Sinne“ eine besondere Wirkung für die Formierung des hochmittelalterlichen Adelsgeschlechtes zu. In seinen Überlegungen zur Selbstvergewisserung agnatisch strukturierter Adelsgeschlechter des 11. und 12. Jahrhunderts wies der Freiburger Historiker auf die Effekte der anhaltenden Bemühung eines Klosters um die Memoria einer Adelsfamilie hin ${ }^{29}$. „Hausklöster“ seien diese Klöster somit, weil sich mit ihnen das „Adelshaus“ ausbildete. Durch die Pflege des Gedächtnisses über Generationen hinweg sei sich das Adelsgeschlecht gleichsam seiner selbst bewusst geworden. Die Vogtei über die Reformneugründungen des 11. und 12. Jahrhunderts sei zudem vom Vater auf den ältesten Sohn übergegangen. Im Gegensatz zur sonstigen adeligen Teilungspraxis verstärkte diese Herrschaftsweitergabe in agnatischer Linie die Ausbildung des Adelsgeschlechts neuen Typs, mit diesem Prozess gehe die Zubenennung nach einer namensgebenden Burg und die Sitzkonzentration einher ${ }^{30}$. Diese in vielfacher Hinsicht immer noch bestechenden Ausführungen weisen den von Adeligen gegründeten und bevogteten Klöstern, in denen diese ihre Grablege fanden und ihre Memoria vollzogen wurde, eine herausragende Bedeutung für die Geschichte des Adels im Hochmittelalter zu. Um Karl Schmid selbst zu Wort kommen zu lassen: „Die Beziehungen der Adelsfamilie zu dem von ihr

${ }^{28}$ Vgl. für diese allgemein verbreitete Verbindung: Harald WinkeL, Herrschaft und Memoria. Die Wettiner und ihre Hausklöster im Mittelalter (Schriften zur sächsischen Geschichte und Volkskunde, Bd. 32), Leipzig 2010, S. 12-16; zu dieser Diskussion differenzierend: Christine Reinle, Ergebnisse und Probleme, in: Mittelalterliche Fürstenhöfe und ihre Erinnerungskulturen, hg. von Carola Fey/Steffen Krieb/Werner Rösener (Formen der Erinnerung, Bd. 27), Göttingen 2007, S. 277-321, hier S. 279f., S. 311-318.

29 Zum Werk von Karl Schmid: Dieter Mertens/Thomas Zotz, Einleitung der Herausgeber, in: Geblüt - Herrschaft - Geschlechterbewusstsein. Grundfragen zum Verständnis des Adels im Mittelalter (Vorträge und Forschungen, Bd.44), Sigmaringen 1998, S. IXXXXIII, hier zum „Hauskloster“, S. XVII und XXIIIf. Erste Überlegungen zu diesem Themenbereich finden sich schon in der Habilitationsschrift, ebd., S. $143 \mathrm{f}$.

${ }^{30} \mathrm{Karl}$ Schmid, Adel und Reform in Schwaben, in: Investiturstreit und Reichsverfassung, hg. von Josef Fleckenstein (Vorträge und Forschungen, Bd.17), Sigmaringen 1973, wieder in: Karl Schмid, Gebetsgedenken und adliges Selbstverständnis im Mittelalter. Ausgewählte Beiträge. Festgabe zu seinem sechzigstens Geburtstag, Sigmaringen 1983, S.336359, hier etwa S.356f., am Beispiel der Habsburger: „Indem Erbteilungen abgewehrt oder ausgeglichen wurden, verdichtete die Familie ihre Herrschaft und bestückte sie nicht nur mit der Mittelpunkt bildenden Burg, sondern bereicherte sie auch durch das Kloster, das sog. ,Hauskloster ‘..., weiter unten dann: „Das habsburgische Hauskloster, das jeweils der älteste des Geschlechts bevogtete, gab der aufstrebenden Adelsherrschaft einen geistlichen Mittelpunkt, der das durch die Stammburg bezeichnete herrschaftliche Zentrum ergänzte.“ 
gestifteten Kloster verdichten sich durch die geradlinig und ungeteilt fortgesetzte Inhaberschaft der Klostervogtei und nun kann man mit Recht von ,Hausklöstern“ sprechen. Solche Klöster werden dann oft zu Familiengrabstätten des Gründergeschlechts - wie z.B. St. Peter im Schwarzwald für die Zähringer - sie werden zu Erbbegräbnisstätten.“31

Diese Zuschreibung von Memorialfunktionen insbesondere an die adeligen Klöster der Hirsauer und Sanblasianer Reformen des 11. und 12. Jahrhunderts wird heute noch geteilt ${ }^{32}$. Trotz aller Verdienste sind mit diesem Ansatz jedoch Probleme verbunden, die man benennen sollte. Am wichtigsten ist, dass die These von der Ausbildung des Adelsgeschlechts und den Effekten des Hausklosters je länger desto mehr kontextlos im Raum steht. Die schon vielfach an der Schmid-These geäußerte Kritik ist hier nicht zu wiederholen ${ }^{33}$. Einschränkend wird man aus Freiburger Sicht sicher anmerken dürfen, dass sich bei der Lektüre der Ausführungen in den grundlegenden Aufsätzen Karl Schmids Manches vielschichtiger und differenzierter liest, als es in der nachfolgenden Forschung operationalisiert wurde. Die Kritik muss also weniger bei Karl Schmid selbst als bei der sogenannten "Schmid-These“ ansetzen, die in der Forschung in vergröberter und vereinfachender Form weiterentwickelt wurde, gerade auch in ihrer international folgenreichen Rezeption bei Georges Duby ${ }^{34}$.

31 Karl Schmid, Zur Problematik von Familie, Sippe und Geschlecht, Haus und Dynastie beim mittelalterlichen Adel. Vorfragen zum Thema „Adel und Herrschaft im Mittelalter“, in: ZGO 105, NF 66 (1957) S. 1-62, wieder in: Ders., Gebetsgedenken und adliges Selbstverständnis im Mittelalter. Ausgewählte Beiträge. Festgabe zu seinem sechzigstens Geburtstag, Sigmaringen 1983, S. 183-244, Zitat hier S. 226.

32 Vgl. die Thesenbildung Schmids in diesem Punkt zusammenfassend: Werner $\mathrm{Hech}^{-}$ BERGER, Adel im fränkisch-deutschen Mittelalter. Zur Anatomie eines Forschungsproblems (Mittelalter-Forschungen, Bd. 17), Ostfildern 2005, S. 308-311.

${ }^{33} \mathrm{Vgl}$. schon den Forschungsbericht von Thomas Zotz und Dieter Mertens in der Einleitung zur posthum herausgegebenen Habilitationsschrift: Mertens/Zotz, Einleitung (wie Anm.29) S.XVIII-XXVIII; Michael Borgolte, Sozialgeschichte des Mittelalters. Eine Forschungsbilanz nach der deutschen Einheit (Historische Zeitschrift, Beihefte NF, Bd. 22), München 1996, S. 195-202, 394-396; Werner Hechberger, Adel, Ministerialität und Rittertum im Mittelalter (Enzyklopädie deutscher Geschichte, Bd.72), München 2004, S.7479; Beate Kellner, Ursprung und Kontinuität. Studien zum genealogischen Wissen im Mittelalter, München 2004, S.70-77; Hechberger, Adel im fränkisch-deutschen Mittelalter (wie Anm. 32) S.206-328; Gerhard Luвісн, Verwandtsein. Lesarten einer politischsozialen Beziehung im Frühmittelalter (6.-11. Jahrhundert), Köln 2008, S. 128-146; Bernhard Jussen, Perspektiven der Verwandtschaftsforschung fünfundzwanzig Jahre nach Jack Goodys „Entwicklung von Ehe und Familie in Europa“, in: Die Familie in der Gesellschaft des Mittelalters, hg. von Karl-Heinz Spiess (Vorträge und Forschungen, Bd.71), Ostfildern 2009, S. 275-324, hier S. XX.

${ }^{34}$ Zur Schmid-These bzw. zur Duby-Schmid-These vgl. Michael Mitterauer, Mittelalter, in: Geschichte der Familie, hg. von Andreas Gestrich/Jens-Uwe Krause/Michael Mitterauer (Europäische Kulturgeschichte, Bd. 1), Stuttgart 2003, S. 160-363, hier S. 161163; zu Duby auch Kellner, Ursprung und Kontinuität (wie Anm. 33) S.72-74. 
Stichpunktartig seien genannt: der Wandel von der kognatischen Sippe zum agnatischen Geschlecht lasse sich nicht erst im 11./12. Jahrhundert feststellen, vielmehr gebe es schon im früheren Mittelalter erkennbar agnatisch strukturierte Adelsverbände - so früh für Bayern nach Wilhelm Störmer oder in jüngerer Zeit nach Regine Le Jan für das Westfrankenreich ${ }^{35}$. Weder haben die Quellen des Früh- und Hochmittelalters eigene Begriffe für die agnatische oder die kognatische Verwandtschaft, noch unterscheiden sie zwischen den Verpflichtungen zur Unterstützung von Verwandten im engeren oder im weiteren Sinne, so hat Hans-Werner Goetz beobachtet ${ }^{36}$. Auch aus spätmittelalterlicher Perspektive stellt sich die mögliche Konzentration auf das agnatische Geschlecht als langgestreckter Prozess dar. Für den Hochadel hat Karl-Heinz Spieß im späten Mittelalter auf das Nebeneinander von Agnaten und Kognaten in den Verwandtschaftsbeziehungen hingewiesen und die Bedeutung der „Heiratsverwandten“ hervorgehoben ${ }^{37}$. Letztlich, so Joseph Morsel, sei das agnatische Adelsgeschlecht ein herrschaftslegitimierendes „Konstrukt" des 15. Jahrhunderts, das neben anhaltenden bilateralen Organisationsprinzipien von Verwandtschaft stehe ${ }^{38}$.

Vor weitem Horizont bestätigte Michael Mitterauer dies in seiner Geschichte der Familie im Mittelalter. Als charakteristisch für das europäisch-christliche Modell der Verwandtschaft sieht er grundsätzlich einen Rückgang der patrilinearen Abstammungsgemeinschaft und die Bedeutung der mit der Gattin neu begründeten

35 Wilhelm Störmer, Adel und Ministerialität im Spiegel der bayerischen Namengebung (bis zum 13. Jahrhundert). Ein Beitrag zum Selbstverständnis der Führungsschichten, in: Deutsches Archiv für Erforschung des Mittelalters 33 (1977) S. 84-152, hier S. 119 ff.; Regine LE Jan, Famille et pouvoir dans le monde franc (VIIe-Xe) siècle. Essai d'anthropologie sociale, Paris 2003.

36 Hans-Werner Goetz, Verwandtschaft im früheren Mittelalter (I): Terminologie und Funktionen, in: Verwandtschaft, Freundschaft, Bruderschaft. Soziale Lebens- und Kommunikationsformen, hg. von Gerhard KRIEGER, Berlin 2009, S. 15-35, hier S. 34; Hans-Werner Goetz, Verwandtschaft im früheren Mittelalter (II) zwischen Zusammenhalt und Spannungen, in: Nomen et Fraternitas. Festschrift für Dieter Geuenich zum 65. Geburtstag, hg. von Uwe Ludwig/Thomas Schilp (Reallexikon der germanischen Altertumskunde/Ergänzungsbände, Bd. 62), Berlin 2008, S. 547-573, hier S. 568.

37 Karl-Heinz Spiess, Familie und Verwandtschaft im deutschen Hochadel des Spätmittelalters (13. bis Anfang des 16. Jahrhunderts) (Vierteljahresschrift für Sozial- und Wirtschaftsgeschichte, Beiheft, Bd.111), Stuttgart 1993, S. 539.

38 Joseph Morsel, Geschlecht und Repräsentation. Beobachtungen zur Verwandtschaftsrekonstruktion im fränkischen Adel des späten Mittelalters, in: Die Repräsentation der Gruppen: Texte - Bilder - Objekte, hg. von Otto Gerhard Oexle/Andrea von HüLSEN-Esch (Veröffentlichungen des Max-Planck-Instituts für Geschichte, Bd. 141), Göttingen 1998, S.259-325; Joseph Morsel, Ehe und Herrschaftsreproduktion zwischen Geschlecht und Adel (Franken, 14.-15. Jahrhundert). Zugleich ein Beitrag zur Frage nach der Bedeutung der Verwandtschaft in der mittelalterlichen Gesellschaft, in: Ehe - Familie - Verwandtschaft. Vergesellschaftung in Religion und sozialer Lebenswelt, hg. von Andreas Holzem/Ines Weber, Paderborn u.a. 2008, S. 191-224, wonach sich der Begriff „Adel“ erst im 15. Jahrhundert ausbilde, verbunden mit den „Diskursen und Praktiken, die diese neue Kategorie konstruierten“. 
Verwandtschaftsfamilie auch für die Hausherrschaft $a^{39}$. Im Verlauf des Mittelalters, insbesondere im 11. und 12. Jahrhundert, verstärkten sich nach Mitterauer die horizontalen Bindungen sogar: „... die Tendenz zur Parallelisierung von kognatischen und affinen Verwandten, das Aufkommen der Patenverwandtschaft, die Ausweitung des Brüdermodells ..." ${ }^{40}$ Letzlich folgt Mitterauer damit der angelsächsischen und französischsprachigen Forschung, deren Position Bernhard Jussen auf folgende Weise resümierte: „Es spreche kein einziges Element mittelalterlicher Verwandtschaft für ein agnatisches System. “41

Auch wenn Karl Schmid immer wieder die anhaltende kognatische Orientierung des Adels im 12. Jahrhunderts betonte, könnte der von ihm beobachtete Wandel noch weit weniger tiefgreifend gewesen sein, als bislang angenommen. Wenn die Forschung aber heute nicht mehr vom Wandel der Familienstruktur im Hochmittelalter überzeugt ist, dann muss auch die Funktion, die Schmid dem „Hauskloster" zugewiesen hat, überdacht werden: der Prozess der Selbstvergewisserung eines Adelsgeschlechts in der Memoria seines (Haus-)Klosters, der zur Betonung der Vater-Sohn-Folge und damit zum agnatischen Geschlecht geführt habe.

Noch aus einer anderen Perspektive haben wir gelernt, daran zu zweifeln, welche Bedeutung jene adelige Gruppenbildung, die wir als Adelsgeschlecht beschreiben, für Adelige des Hochmittelalters hatte. Gerhard Lubich hat in seiner Habilitationsschrift nach einer semantischen Analyse der Begriffe für „Verwandtschaft“ auch die Bedeutung des „Verwandt-Sein“ für politische Bindungen erörtert ${ }^{42}$. Merkwürdig unscharf bleibe demnach Verwandtschaft in ihrer genealogischen Tiefendimension auch noch um 1100; der im Denken an das Verwandt-Sein am ehesten erfasste Kreis umschließe die „Kernfamilie“ - Vater, Mutter und Kinder so wie die Geschwister und durch Verschwägerung neu gewonnene Verwandte. Das Adelsgeschlecht dagegen spielt für die Untersuchungszeit Lubichs vor 1100 so gut wie keine Rolle. Im 12. Jahrhundert ließen sich an diese Ergebnisse die bekannten Beobachtungen von Werner Hechberger anschließen: den divergierenden, oft überraschenden politischen Ausrichtungen einzelner staufischer oder welfischer Familienangehöriger, bei denen wir ebenfalls das postulierte Denken in intergenerationellen Verwandtschaftszusammenhängen vermissen ${ }^{43}$. Allein in der Familie im engeren Sinne, der Kernfamilie, und den angeheirateten Verwandten dürfen wir im 12. Jahrhundert häufig die politisch relevanten Verwandten eines Adeligen sehen. Doch war nicht gerade das „Hauskloster“ der Ort, an dem die Verbindung zwischen Lebenden und Toten gepflegt wurde und damit aus der Erinnerung das Adelsgeschlecht erwuchs?

\footnotetext{
39 Mitterauer (wie Anm. 34).

40 Ebd., S. 355.

${ }^{41}$ Jussen (wie Anm. 33) S. 281.

42 Lubich, Verwandtsein (wie Anm. 33) S. 124-127.

${ }^{43}$ Werner Hechberger, Staufer und Welfen, 1125-1190. Zur Verwendung von Theorien in der Geschichtswissenschaft (Passauer Historische Forschungen, Bd. 10), Köln 1996.
} 


\section{Gescheiterte Hausklöster - Gescheiterte Memoria?}

Untersucht man die Klostergründungen des Adels im 11. und 12. Jahrhundert darauf hin, ob sie als dauerhafte Grablege eines Adelsgeschlechts fungierten und ihnen im ausgeführten Sinne Hausklosterqualität zukommen konnte, dann ist das Ergebnis erstaunlich ernüchternd. An vier Beobachtungen sei festgehalten, weshalb Klöster in vielen Fällen nicht den zugeschriebenen Effekt als „Hauskloster“ für die Ausbildung des agnatischen Geschlechts haben konnten.

Erstens ist das zeitliche Nacheinander von Klostergründungen und der Ausbildung des Adelsgeschlechts nur selten in dem Sinne zu beobachten, in dem es eigentlich plausibel wäre. „Gründet man ein Hauskloster? “ so hat Werner Hechberger in einem wichtigen Aufsatz rhetorisch gefragt ${ }^{44}$, anders gewendet: Ist es vorstellbar, dass ein Adeliger ein Kloster mit der Intention stiftete, in diesem Kloster solle sich künftig das Selbstverständnis seiner Familie herauskristallisieren? Eine solche Annahme wäre offensichtlich widersinnig. Auch ein später eng mit einem Adelsgeschlecht verbundenes Kloster muss zu Beginn aus anderen Motiven errichtet worden sein. Erst nach Jahrzehnten oder über Generationen hinweg wäre es möglich, durch die Memoria der verstorbenen Angehörigen und die kontinuierliche Weitergabe der Vogtei in den Händen der Stifterfamilie, die skizzierten Effekte anzunehmen. Eine derartige zeitliche Aufeinanderfolge lässt sich aber nur selten beobachten. In der Regel setzt mit der Gründung des Hausklosters eine Quellenüberlieferung ein, in welcher der stiftende Adelige und sein familiäres Umfeld klar hervortreten, häufig sogar schon mit der Zubenennung nach einer namengebenden Burg. Zum Zeitpunkt der Klostergründung hatte das Adelsgeschlecht somit, bleibt man im Schmidschen Modell, schon eine gewisse Festigung erreicht.

Die Zähringer etwa errichteten ab 1093 ihr Kloster St. Peter auf dem Schwarzwald. Schon in den ersten Einträgen des Rotulus Sanpetrinus, die zwischen 1109 und 1111 zu datieren sind, wird die Familie erkennbar ${ }^{45}$. Wir erfahren in einer Serie von Notizen von Güterübertragungen im Umfeld des Todes des Gründers, Herzog Bertholds II. von Zähringen (1092-1111), dass seine Gemahlin Agnes hieß, sein Bruder Bischof Gebhard III. von Konstanz war und er Söhne mit den Namen Berthold, Rudolf und Konrad und einen Neffen Hermann hatte ${ }^{46}$. Als nach dem Tod

44 Werner Hechberger, Konrad III. - Königliche Politik und „staufische Familieninteressen“?, in: Grafen, Herzöge, Könige. Der Aufstieg der frühen Staufer und das Reich (10791152), hg. von Hubertus Seibert/Jürgen Dendorfer (Mittelalter-Forschungen, Bd. 18), Ostfildern 2005, S. 323-340, hier S. 328.

${ }^{45}$ Die ältesten Güterverzeichnisse des Klosters St. Peter im Schwarzwald. Der Rotulus Sanpetrinus und Fragmente eines Liber monasterii sancti Petri. Edition, Übersetzung und Abbildung, bearb. von Jutta Krimm-Beumann (VKgL A 54), Stuttgart 2011, R1-R3, S. 2-11; zur Datierung der ersten Güterübertragungen vgl. die Einleitung, S.XLIVf.; zur Gründung von St. Peter nun: Jutta Krimm-Beumann, monasterium conditum-transtulit - fundavit, in: ZGO 161 (2013) S. 43-58.

46 Güterverzeichnisse des Klosters St. Peter (wie Anm. 44) R 2 f., S. 5-10. 
Herzog Bertholds II. 1111 seine Söhne ein Gut an das Kloster gaben und die Schenkungen ihrer Vorfahren bestätigten, werden auch die Eltern Bertolds II. und seiner Frau Agnes erwähnt, an der Spitze steht dabei der Vater der Agnes, König Rudolf von Rheinfelden. Somit tritt gerade der kognatische und nicht der agnatische Bezug hervor, der mit Herzog Berthold I. und seiner Gemahlin Richwara ebenfalls erwähnt wird. Schon in den ersten ausführlicheren Notizen des Klosters, etwa fünfzehn Jahre nach seiner Gründung, erfahren wir etwas über den Stifter und seine Frau, deren Eltern und ihre Söhne. Bildeten sich die Zähringer als Adelsgeschlecht aber durch diese Gründung heraus? Die ersten Nennungen nach der Burg Zähringen - im Schmidschen Sinne ein wichtiger Indikator - finden sich schon vor diesen Zeugnissen aus St. Peter in St. Blasianer und Schaffhausener Urkunden von 1100 und $1102^{47}$.

Zweitens konnten die gegründeten Klöster die Aufgabe der kontinuierlichen Erinnerungspflege häufig gar nicht erfüllen, denn nicht selten veränderten sich die Orte der Memoria einer adeligen Familie von Generation zu Generation. Das prominenteste Beispiel bieten die Staufer, die wie Hansmartin Schwarzmaier festgestellt hat, „in jeder Generation, in der sie die Führung in Schwaben übernommen haben, jeweils ein neues ,Hauskloster ' gründeten“48. Das von Herzog Friedrich I. $(† 1105)$ vor 1102 errichtete Kloster Lorch wies dabei nie die Funktionen eines kontinuierlichen Hausklosters der Staufer auf ${ }^{49}$. Schon der Sohn Herzog Friedrichs I., Herzog Friedrich II. von Schwaben, ließ sich nicht mehr dort, sondern in St. Walburg im Elsass bestatten ${ }^{50}$. Sein Bruder König Konrad III. wurde, obwohl er viel-

47 Thomas ZотZ, Dux de Zaringen - dux Zaringiae. Zum zeitgenössischen Verständnis eines neuen Herzogtums im 12. Jahrhundert, in: ZGO 139 (1991) S.1-44, hier S.16f.; Krimm-Beumann, monasterium (wie Anm. 45) S. 47f.; Quellenbelege: Urkundenbuch des Klosters St. Blasien im Schwarzwald. Von den Anfängen bis zum Jahr 1299, bearb. von Johann Wilhelm Braun (VKgL A 23,1), Stuttgart 2003, Nr. 74, S. 89 f., hier S. 90 „Berchtold de Zeringen" (allerdings aus dem Liber constructionis um 1400); Das Kloster Allerheiligen in Schaffhausen, hg. von Franz-Ludwig Baumann, in: Die ältesten Urkunden von Allerheiligen in Schaffhausen, Rheinau und Muri (Quellen zur Schweizer Geschichte, Bd. 3/3), Basel 1883, Nr. 39, S. 65-67, „cum duce Bertholdo de Zaringen“.

${ }^{48}$ Hansmartin Schwarzmaier, Die monastische Welt der Staufer und Welfen im 12. Jahrhundert, in: Von Schwaben bis Jerusalem. Facetten staufischer Geschichte, hg. von Sönke Lorenz/Ulrich Sснмidt (Veröffentlichungen des Alemannischen Instituts, Bd. 61), Sigmaringen 1995, 241-259, jetzt auch in: Hansmartin Schwarzmaier, Klöster, Stifter, Dynastien. Studien zur Sozialgeschichte des Adels im Hochmittelalter, hg. von Konrad Krimm/ Peter RüCKent (VKgL B 190), Stuttgart 2012, S. 53-74, hier das Zitat S. 56, insgesamt S. 56 f.

${ }^{49}$ Vgl. allerdings den Versuch einer Differenzierung, Lorch als Hauskloster der Staufer als Herzogsfamilie - nicht als Königsfamilie - einzuordnen: Hans-Martin MaUrer, Zu den Anfängen Lorchs als staufisches Hauskloster, in: 900 Jahre Kloster Lorch. Eine staufische Gründung vom Aufbruch zur Reform. Beiträge einer Tagung des Württembergischen Geschichts- und Altertumsvereins am 13. und 14. Februar 2002 in Lorch, hg. von Felix Heinzer/Robert Kretzschmar/Peter Rückert (VKgL), Stuttgart 2004, S.1-28, zur staufischen Familiengrablege, S. 17-19.

50 Eduard Hlaw itschka, Die Ahnen der hochmittelalterlichen deutschen Könige, Kai- 
leicht in Lorch begraben werden wollte, in Bamberg zur letzten Ruhe gebettet ${ }^{51}$. Bemerkenswert ist jedoch, dass seine früher verstorbene Gemahlin, Königin Gertrud, und ihr Sohn, Friedrich von Rothenburg, in der fränkischen Zisterze Ebrach ihr Grab fanden ${ }^{52}$. Die staufischen Nachfolger Konrads als Kaiser und Könige wählten dann gänzlich andere, weitaus prestigeträchtigere Grablegen als das Kloster im Remstal ${ }^{53}$.

Ein Seitenblick auf die Welfen verdeutlicht ebenfalls, dass erweiterte Möglichkeiten und ein neues Rangbewusstsein auch bei ihnen zu neuen Memorialstrategien führten. Von der Jahrtausendwende bis in das Jahr 1126 war die Sorge um die Memoria der Familie in Altdorf, nach 1055 dann im Kloster Weingarten konzentriert, in unmittelbarer räumlicher Nähe wurden offenbar mehrere Generationen der Familie bestattet ${ }^{54}$. Sicheren Quellengrund erlangen wir zwar erst nach dem „Dynastiesprung“ von 1055 und dem damit verbundenen Konventswechsel zwischen Weingarten und Altomünster, aber auch von da an ist die Kontinuität noch beeindruckend: von Herzog Welf III. über Herzog Welf IV. und seine Frau Judith, Herzog Welf V. und Herzog Heinrich den Schwarzen mit Wulfhild fanden über einen Zeitraum von mehr als 70 Jahren drei Generationen in Weingarten ihr Grab. Bei Herzog Heinrich dem Stolzen, dem Herzog von Bayern und Sachsen, schlugen sich der gesteigerte Rang und die Erweiterung der Handlungsräume jedoch in einem neuen Ort nieder: Er fand in der sächsischen Kaisernekropole Königslutter, an der Seite Kaiser Lothars III., sein $\mathrm{Grab}^{55}$. Sein Sohn Heinrich der Löwe in

ser und ihrer Gemahlinnen. Ein kommentiertes Tafelwerk, Bd. II: 1138-1197 (MGH Hilfsmittel 26), Hannover 2009, S. 90 f. mit Quellenbelegen.

51 Ebd., S.6f.

52 Ebd., S.53f., mit Quellenbelegen. Dazu: Ferdinand Geldner, Um die frühen Staufer-Gräber in Ebrach, Lorch und Bamberg, in: Festschrift Ebrach. 1127-1977, hg. von Gerd Zimmermann, Volkach 1977, S. 38-52 (vor allem zum vermutlichen Grab König Heinrichs [VI.]); zu den heute greifbaren Gräbern und ihrer architektonischen Gestalt: Markus HöRsch, Die mittelalterlichen Bildwerke in der Abtei Ebrach und ihre Bedeutungen. Interessen und Hierarchien in einer Grabeskirche, in: Neue Forschungen zur mittelalterlichen Bau- und Kunstgeschichte in Franken. Vorträge der Ringvorlesung des Zentrums für Mittelalterstudien der Otto-Friedrich-Universität Bamberg im Sommersemester 2010, hg. von Achim Hubel (Bamberger interdisziplinäre Mittelalterstudien/Vorträge und Vorlesungen, Bd. 2), Bamberg 2011, S. 77-112, hier S. 81 f., 89-98.

53 Olaf B. RAder, Die Grablegen der Staufer als Erinnerungsorte, in: Verwandlungen des Stauferreiches. Drei Innovationsregionen im mittelalterlichen Europa, hg. von Bernd Schneidmüller/Stefan Weinfurter/Alfried Wieczorek, Darmstadt 2010, S. 20-33.

${ }^{54}$ Klärend, die ältere Literatur erschließend: Sönke Lorenz, Weingarten und die Welfen, in: Welf IV. - Schlüsselfigur einer Wendezeit. Regionale und europäische Perspektiven, hg. von Dieter R. BAuer/Matthias Becher (Zeitschrift für bayerische Landesgeschichte, Reihe B, Beiheft 24), München 2004, S.30-55.

55 Bruno Klein, Die ehemalige Abteikirche von Königslutter. Die Grablege eines sächsischen Kaisers am Beginn der Stauferzeit, in: Heinrich der Löwe und seine Zeit. Herrschaft und Repräsentation der Welfen 1125-1135. Katalog der Ausstellung Braunschweig 1995, Bd.2: Essays, hg. von Jochen Luckhardt/Franz Niehoff, München 1995, S. 105-119; 
Braunschweig; dessen Onkel Welf VI. schließlich errichtete in Steingaden eine Grablege für sich und seinen früh verstorbenen Sohn Welf VII. ${ }^{56}$ Diese Klosterund Stiftsgründungen schlossen das anhaltende Gedenken an die Vorfahren an bestehenden Memorialorten zwar nicht aus, Hausklöster im engeren Sinn, ausgezeichnet durch eine dauerhafte Grablege mit der Herrschaftsweitergabe über die Vogtei in der Vater-Sohn-Linie, waren dies aber nicht.

Besonders deutlich wird das sich hier abzeichnende Gründungsmotiv, die Sorge um das eigene Seelenheil und das der engeren Familie, in jenen Fällen, in denen Klöster nur für die eigene Memoria der Stifter gegründet worden sein können, weil das Ende der Adelsfamilie zum Stiftungszeitpunkt absehbar war: Zwiefalten etwa, das durch die Chroniken Ortliebs und Bertholds des 12. Jahrhunderts ausnehmend gut dokumentiert ist, pflegte das Andenken der Gründerfamilie von Achalm, insbesondere der Stifter Kuno und Luitold, die beide keine erbberechtigten Söhne hatten und mit denen die Familie schon ihr Ende fand ${ }^{57}$. Wiederum eine andere Fallgruppe kann man in denjenigen Klöster sehen, in denen Adelsfamilien in der Generation nach der Gründung ausstarben: die Grafen von Nellenburg endeten in männlicher Linie mit dem Sohn des Stifters des Klosters Allerheiligen in Schaffhausen, Burkhard $(1101 / 1102)^{58}$. Die Memoria der Gründerfamilie aber war bis heute erfolgreich, wie das Epitaph der Stifterfamilie in Schaffhausen zeigt ${ }^{59}$. Ein über mehrere Generationen hinweg belegtes Hauskloster für das Adelsgeschlecht wurde Allerheiligen aber nicht.

„Nicht Ruh’ im Grabe ließ man euch ...“ Die letzte Heimat Kaiser Lothars III. im Spiegel naturwissenschaftlicher und historischer Forschungen, hg. von Tobias Henkel, Braunschweig 2012.

${ }^{56}$ Katrin BaAken, Herzog Welf VI. und seine Zeit, in: Welf VI. Wissenschaftliches Kolloquium zum 800. Todesjahr vom 5. bis zum 8. Oktober $1991 \mathrm{im} \mathrm{Schwäbischen} \mathrm{Bildungszen-}$ trum Irsee, hg. von Rainer JeHL (Irseer Schriften, Bd. 3), Sigmaringen 1995, S. 9-28, hier vor allem S. 23-28, zur besonderen Förderung Steingadens durch Welf VI.

57 Sönke Lorenz, Graf Liutold von Achalm (†1098) - ein Klosterstifter im Zeithorizont des Investiturstreits, in: Liutold von Achalm (†1098). Graf und Klostergründer. Reutlinger Symposium zum 900. Todesjahr, hg. von Heinz Alfred Gemeinhardt, Reutlingen 2000, S. 11-55, hier S. 50-53; Rolf Kuithan, Die Benediktinerabtei Zwiefalten in der kirchlichen Welt des 12. Jahrhunderts. Ein Beitrag zur Untersuchung der Zwiefalter Memorialquellen. Bestandteil des Quellenwerkes Societas und fraternitas, Münster 1997.

${ }^{58}$ Kurt Hils, Die Grafen von Nellenburg im 11. Jahrhundert. Ihre Stellung zum Adel, zum Reich und zur Kirche (Forschungen zur oberrheinischen Landesgeschichte, Bd. 19), Freiburg 1967; Alfons ZetTLeR, Nellenburg - Kloster Reichenau - Allerheiligen in Schaffhausen. Stationen in der Geschichte der älteren Nellenburger, in: Das Kloster Allerheiligen in Schaffhausen. Zum 950. Jahr seiner Gründung am 22. November 1049, hg. von Kurt BäNteli/Rudolf Gamper/Peter Lehmann (Schaffhauser Archäologie, Bd.4), Schaffhausen 1999, S. 146-154.

${ }^{59}$ Hans Seeliger, Die Grabplatten der Grafen von Nellenburg und die Nellenburger Memorialtafel im Museum zu Allerheiligen in Schaffhausen, in: Schaffhauser Mitteilungen zur vaterländischen Geschichte 49 (1972) S. 9-52; Hans Lieв, Die frühen Inschriften des Klosters Allerheiligen, in: Kloster Allerheiligen (wie Anm. 58) S. 155-157. 
Nimmt man diese Beobachtungen zusammen, die jeweils individuellen Memorialstrategien einzelner Generationen eines Adelsgeschlechts oder besser einzelner Adeliger, die Klostergründungen die von Anfang erkennbar als Gedächtnis- und Memorialort für eine Familie entstanden sind - für sie schlug Helmut Flachenecker den Terminus Gedächtniskloster vor ${ }^{60}$ - und die gezwungenermaßen durch das Aussterben einer Familie auf eine Generation beschränkten Fälle, dann bleiben nur wenige Beispiele für das „Hauskloster“ im klassischen Vorverständnis übrig: die kontinuierliche Grablege und der Memorialort einer Adelsfamilie. Auch solche gibt es. St. Peter auf dem Schwarzwald war im 12. Jahrhundert offenbar die alleinige Grablege der Zähringer deren Vogtei im Senioratsprinzip weitergegeben wur$\mathrm{de}^{61}$, auch wenn man anfügen darf, dass der letzte Zähringer Berthold V. 1218 mit dieser Tradition brach und sich im Freiburger Münster bestatten ließ ${ }^{62}$.

Drittens gründete mitunter nicht nur ein Adeliger, sondern eine Gruppe von Adeligen ein Kloster. Häufig sind dies Angehörige eines Verwandtenkreises, den man nicht treffend als Adelsgeschlecht bezeichnen kann. Erbengemeinschaften mögen eine Rolle spielen, die Verbindung der Adeligen durch Heiraten und Verschwägerung kann aber neben erbbedingter verwandtschaftlicher Nähe auch auf andere Motivationen hinweisen. Die vier Edelfreien, die Bronnbach gründeten, waren etwa in solchen unübersichtlichen verwandtschaftlichen Beziehungen miteinander verwoben ${ }^{63}$.

Ein anderes, lehrreiches Beispiel wäre der Stifterkreis des im Jahre 1095 gegründeten Klosters Alpirsbach: Rutmann von Hausen, Adalbert von Zollern und Graf Alwig von Sulz errichteten das Kloster im oberen Kinzigtal. Über die Motive lässt sich spekulieren, die früheste zeitgenössische Traditionsnotiz um 1100 nennt die Hoffnung auf himmlischen Lohn ${ }^{64}$. Auf bis heute nicht ganz eindeutig geklärten

${ }^{60}$ Helmut Flachenecker, Schweinfurter Haus- und Gedächtnisklöster, in: Vor 1000 Jahren - die Schweinfurter Fehde und die Landschaft am Obermain 1003, hg. von Erich Schneider, Schweinfurt 2004, S. 101-116, beobachtet, dass zwei Töchter des letzten „Grafen" von Schweinfurt, Herzog Otto von Schwaben (†1057), als sich das Aussterben der Familie abzeichnete, Klöster in Burgen der Familie gründeten. Diese seien nicht als „Hausklöster“, sondern zutreffender als „Gedächtnisklöster" zu bezeichnen (hier S. 105).

${ }^{61}$ Thomas ZотZ, St. Peter unter den Zähringern und unter den Grafen von Freiburg. Hausklosterfunktion und Vogteifrage, in: Das Kloster St. Peter auf dem Schwarzwald. Studien zu seiner Geschichte von der Gründung im 11. Jahrhundert bis zur frühen Neuzeit, hg. von Hans-Otto Mühleisen/Hugo Oтт/Thomas Zotz (Veröffentlichung des Alemannischen Instituts Freiburg i.Br., Bd.68), Waldkirch 2001, S. 51-78.

62 Berent SCHwineköPer, Hochmittelalterliche Fürstenbegräbnisse, Anniversarien und ihre religiösen Motivationen. Zu den Rätseln um das Grab des letzten Zähringers (Bertold V. 1186-1212), in: Person und Gemeinschaft im Mittelalter. Karl Schmid zum fünfundsechzigsten Geburtstag, hg. von Gerd Althoff u. a., Sigmaringen 1988, S. 491-539.

${ }_{63}$ Vgl. dazu die oben Anm. 6-9 angegebene Literatur.

${ }^{64}$ Sönke Lorenz, Gründung und Frühzeit. Kloster Alpirsbach zwischen St. Blasien und Hirsau, in: Alpirsbach. Zur Geschichte von Kloster und Stadt, hg. von Landesdenkmalamt Baden-Württemberg (Landesdenkmalamt Baden-Württemberg. Forschungen und Berichte 
Wegen besaßen die drei Stifter ein gemeinsames Erbgut, beachtenswerter als diese besitzrechtliche Grundlage erscheint aber, dass sie im Jahr 1095 die Entscheidung zur Gründung einer von St. Blasien aus besiedelten Abtei trafen und zusammen handelten. Würden wir das Kloster allein als Memorialort eines Adelsgeschlechts betrachten, dann würde gerade dieses Zusammenwirken verschiedener Adeliger zur Gründung nicht mehr sichtbar, das für den Historiker besonders reizvoll ist. Als in Alpirsbach nach erheblichen Verwerfungen die Zollern im 12. Jahrhundert die Vogtei innehatten, hätte dieses in der Tat über die nachfolgenden Generationen hinweg die gewünschten Hausklostereffekte entfalten können ${ }^{65}$.

Ein letzter, vierter Punkt, darf bei einer kritischen Analyse der tatsächlichen Memorialfunktion hochmittelalterlicher Hausklöster nicht fehlen. Ein Quellenproblem, das eigener Erörterung bedürfte und diese zum Teil auch schon gefunden hat. Gerade in Krisenzeiten geistlicher Gemeinschaften erinnerte man sich gerne an die Stifter. Etwa dann, wenn mit dem Aussterben eines Vogtgeschlechts nicht nur potentielle Bedrücker, sondern auch die Förderer des Klosters wegzufallen drohten. In solchen Situationen entstanden in Klöstern „Hausgeschichten“ adeliger Familien, die, wie unter anderem Gerd Althoff herausgearbeitet hat, ganz wesentlich aus den Interessen und Motiven des Klosters selbst gestaltet wurden, etwa mit der Absicht für das Kloster zu werben ${ }^{66}$. Die bei solchen Gelegenheiten verschriftlichte Erinnerung an Stifter und Wohltäter hob Kontinuitäten hervor, wo keine waren, sammelte Nachrichten über im Kloster tatsächlich oder nur vermeintlich bestattete Angehörige einer Adelsfamilie und warf nicht zuletzt aus dem Wissen um die Zukunft auch charakteristische Akzente auf die Gründungsumstände eines Klosters. Dieser in der Quellenlage liegenden Gefahr sollte man sich bewusst bleiben. Für jedes angebliche Hauskloster wäre zu überprüfen, inwieweit hier nicht späte oder sogar sehr späte Quellen Zusammenhänge und Kontinuitäten herstellen, wo keine waren. Ein im letzten Jahrzehnt intensiv diskutiertes Beispiel dafür ist die Überlieferung, die im Kloster Lorch im 15. Jahrhundert zur Staufergenealogie entstand ${ }^{67}$. Das sogenannte Lorcher Rote Buch ist jenseits seiner kreativen Aus-

der Bau- und Kunstdenkmalpflege, Bd.10), Stuttgart 2001, S. 15-32, sowie Hans Harter, Predium Alpirspach dictum. Der Ort der Klostergründung und seine Besitzer, in: ebd., S. 33-66, zu den Motiven Harter, Predium, S. 62 f.

${ }^{65}$ Harter, Predium (wie Anm. 64) S. 62 f.

${ }^{66} \mathrm{Zu}$ dieser Diskussion, die von Thesen Hans Patzes zur Adeligen Hausüberlieferung ausging: Gerd Althoff, Anlässe zur schriftlichen Fixierung adligen Selbstverständnisses, in: ZGO 134 (1986) S. 34-46; vgl. dazu die weiterführenden Fallstudien von Stefan TeвRuck, Die Reinhardsbrunner Geschichtsschreibung im Hochmittelalter. Klösterliche Traditionsbildung zwischen Fürstenhof, Kirche und Reich (Jenauer Beiträge zur Geschichte, Bd.4), Frankfurt a. Main 2001; Stefan PäTzold, Adel - Stift - Chronik. Die Hausüberlieferung der frühen Wettiner, in: Adlige - Stifter - Mönche. Zum Verhältnis zwischen Klöstern und mittelalterlichem Adel, hg. von Nathalie KrupPA (Veröffentlichungen des Max-Planck-Instituts für Geschichte, Bd. 227), Göttingen 2007, S. 135-182; Winkel (wie Anm. 28).

${ }^{67}$ Klaus Graf, Staufer-Überlieferungen aus Kloster Lorch, in: Von Schwaben bis Jerusalem. Facetten staufischer Geschichte, hg. von Sönke Lorenz/Ulrich Schmidt (Veröffentli- 
legung durch Hansmartin Decker-Hauff an sich ein charakteristischer spätmittelalterlicher Versuch einer großzügig übertreibenden Staufermemoria.

Von Hausklöstern zu sprechen, so darf man zusammenfassen, macht dann nur selten Sinn, wenn wir davon ausgehen wollten, dass diese tatsächlich in der Memoria einer adeligen Familie zur Ausbildung eines Geschlechterbewusstseins beitrugen; das zeitliche Nebeneinander der Gründung von Klöstern und der Ausprägung eines Adelsgeschlechts, die erstaunlich häufigen Wechsel von Memorialorten innerhalb von Generationen, die Tatsache, dass Klöster gelegentlich nicht nur von einer Familie gegründet wurden, sondern von mehreren Adeligen und nicht zuletzt die Gefahr nachträglicher Kontinuitätsfiktionen in der Haushistoriographie der Klöster - all dies mahnt zur Vorsicht, Klostergründungen von Adeligen vorschnell als „Hausklöster“ zu charakterisieren.

Neue Deutungszusammenhänge eröffnen sich aber, wenn man nicht a priori annimmt, dass Klöster mit dem Ziel gegründet wurden, als Grablege und Memorialort für ein ganzes Adelsgeschlecht zu dienen. Verengt man die Absichten der Gründer und die Funktion des Klosters nicht auf diese Deutung als „Hauskloster“, dann bietet sich eine Fülle von möglichen Motiven, die Adelige dazu bewegte, Klöster zu gründen.

\section{Motive und Funktionen adeliger Klostergründungen des Hochmittelalters}

Als wichtigster Antrieb für adelige Klostergründungen wird in zeitgenössischen Quellen die Sorge der Stifter um das eigene Seelenheil hervorgehoben, für das sie sich das anhaltende Gebet des Konvents sichern wollten. Aus diesem Grund ließen sich der Gründer und seine Familie im Kloster, in der Kirche oder im Kapitelsaal, bestatten. Dieser „Memorialvertrag“ zwischen Stifter und Konvent steht am Anfang jeder Klostergründung ${ }^{68}$. Sichtet man die Urkunden des Hochmittelalters auf ihre Begründungen für die Ausstattung durch Adelige, dann wird dieser Aspekt sicher am Häufigsten genannt. Zu unterscheiden wäre aber, ob hier ein Adeliger auf sein eigenes Seelenheil, das seiner Familie im engeren Sinn, d.h. seiner Gemahlin oder seiner Kinder, bedacht war oder ob er prospektiv auch für seine Nachfahren vorsorgen wollte. Bemerkenswert ist nun, dass es Zeugnisse gibt, in denen die Einbindung von Söhnen oder auch weitschichtiger Verwandter bei Klostergründungen explizit damit begründet wurde, dass auf diese Weise künftige Anfechtungen ver-

chungen des Alemannischen Instituts Freiburg i.Br., Bd. 61), Sigmaringen 1995, S. 209-240; Gerd Luвich, Auf dem Weg zur „Güldenen Freiheit“. Herrschaft und Raum in der Francia orientalis von der Karolinger- zur Stauferzeit (Historische Studien, Bd. 449), Husum 1996, S. 246-261; Klaus Graf, Staufertraditionen in Kloster Lorch, in: 900 Jahre Kloster Lorch (wie Anm. 49) S.165-173.

68 Streich (wie Anm. 18) S. 44; Winkel (wie Anm. 28) S. 16. 
mieden werden sollten ${ }^{69}$. Die Akteure selbst kalkulierten offensichtlich Störungen bei der Verwirklichung ihres Stifterwillens mit ein ${ }^{70}$. Im Zentrum des Gedächtnishorizonts sollten der Stifter selbst und seine mitlebende Generation stehen, darauf verweisen auch die zahlreichen Gründungen von söhnelosen Adeligen in namengebenden Burgen ihrer Familie ${ }^{71}$.

Teilt man die hier entwickelte Annahme, dass Klostergründungen des Hochmittelalters stärker als bisher beachtet auch Memorialstrategien einzelner Adeliger und ihrer engeren Familie waren, dann eröffnet dies neue Deutungsmöglichkeiten. Im Akt der Klostergründung erschließt sich eine Dimension der persönlichen Memoria eines Adeligen. In der auf diese Weise greifbaren sakralen Herrschaftsrepräsentation werden Ansprüche und Selbstdeutungen ebenso sichtbar wie personale Beziehungen adeliger Individuen. Ein Schlaglicht auf zwei besonders herausragende Beispiele, in etwa am Beginn und am Ende des Untersuchungszeitraums, mag dies verdeutlichen. Die oktogonale Imitation der Aachener Pfalzkapelle in Ottmarsheim (bei Mulhouse) ist eine bis heute eindrückliche, bauliche Manifestation herausragender persönlicher Memoria ${ }^{72}$. Mitten in der Kirche ließ sich wohl Rudolf von Altenburg, der ohne männliche Nachkommen verstorbene Stifter, sein Grab errichten ${ }^{73}$. Auch wenn Rudolf in den genealogischen Horizont der frühen

${ }^{69}$ Vgl. etwa die Urkunde aus dem Jahr 1156, mit der Markgraf Konrad von Wettin ( $\left.† 1157\right)$ den Bestand des Stiftes Lauterberg absichern wollte (Codex Diplomaticus Saxoniae regiae, hg. von Otto Posse/Hubert Ermisch, Bd. I,2, Leipzig 1889, Nr. 262, S. 176-179). Diese Urkunde ist auch als Versuch Markgraf Konrads zu lesen, seine Söhne auf seine Gründung zu verpflichten, was diese allerdings nicht davon abhielt, jeweils neue „Hausklöster“ zu errichten. Vgl. Winkel (wie Anm. 28) S. 78-94.

70 Die Probleme der Verstetigung von Stiftungen untersucht: Claudia Moddelmog, Königliche Stiftungen des Mittelalters im historischen Wandel. Quedlinburg und Speyer, Königsfelden, Wiener Neustadt und Andernach (StiftungsGeschichte, Bd. 8), Berlin 2012.

${ }_{71} \mathrm{Vgl}$. oben Flachenecker (wie Anm. 60); Streich (wie Anm. 18) S. 46-54, und passim, hier etwa S. 53: „Bei allen statistischen Unwägbarkeiten bleibt festzuhalten, daß es sich bei den meisten hochmittelalterlichen Klostergründungen mehr oder weniger deutlich verifizierbar um solche ,Erinnerungsklöster‘ handelt.“

$72 \mathrm{Zu}$ Ottmarsheim als Imitation der Aachener Pfalzkapelle: Albert Verbeek, Zentralbauten in der Nachfolge der Aachener Pfalzkapelle, in: Das erste Jahrtausend. Kultur und Kunst im werdenden Abendland an Rhein und Ruhr, Textband II, Düsseldorf 1964, S. 898947, hier S. 928-931; Matthias Untermann, Der Zentralbau im Mittelalter. Form, Funktion, Verbreitung, Darmstadt 1989, S. 120-147 („Kopien“ der Aachener Pfalzkapelle), hier S. 134136, sowie S. 264; zur Datierung der Kirche und zu ihrer Einbettung in die Architektur des 11. Jahrhunderts im Elsass: Jean-Philippe Meyer, Les églises du XIe siècle en Alsace et les débuts de l'architecture salienne, in: Léon IX et son temps. Actes du colloque international organisé par l'Institut d'Histoire Médiévale de l'Université Marc-Bloch, Strasbourg-Eguisheim, 20- 22 juin 2002, hg. von Georges Bischoff/Benoit-Michel Tock (Atelier de Recherches sur les Textes Médiévaux), Turnhout 2006, S. 495-529, hier $502 \mathrm{f}$.

${ }^{73} \mathrm{Zu}$ diesem erst in den 80er Jahren entdeckten Stiftergrab im Zentrum der Kirche vgl. Pierre BRUneL, In Erwartung des jüngsten Gerichts, in: Leben im Mittelalter. 30 Jahre Mittelalterarchäologie im Elsass, hg. von Meinard Maria Grewening/Andrea Nisters, Speyer 1992, S. 233-244, hier S. 234 und 236. 
Habsburger eingeordnet werden kann, ist Ottmarsheim zum Zeitpunkt der Gründung kein Hauskloster der Habsburger, die es zu diesem Zeitpunkt als Adelsgeschlecht noch nicht gab. Später aber wird das Benediktinerinnenkloster zu einem Ort des habsburgischen Gedenkens an die Vorfahren ${ }^{74}$. Auch noch im 12. Jahrhundert darf man auf Memorialstrategien bedeutender Adeliger verweisen; die Grablege, die sich Heinrich der Löwe in der Stiftskirche seiner Braunschweiger Burgpfalz Dankwarderode schuf, kann exemplarisch dafür stehen ${ }^{75}$.

Das Bemühen um das eigene Andenken schuf diese Anlage, in den im Zuge der Memoria in den jeweiligen Klöstern und Stiften entstandenen Quellen spiegelte sich zwar möglicherweise auch das historische Selbstverständnis eines Adelsgeschlechts, entscheidender waren aber zum Gründungszeitpunkt die Beziehungen des Gründers selbst. Wie bei Klostergründungen, so zeigen sich auch in den Schenkungen Adeliger zum Seelenheil an mehrere Klöster und Stifter ihre Bindungen. An der dichten Traditionsbuchüberlieferung Bayerns im 11. und 12. Jahrhundert lässt sich beobachten, dass dann, wenn Adelige an mehrere Klöster und Stifte schenkten oder gar annähernd vollständige testamentarische Legate überliefert sind, sich abhängig vom Verfügenden der Kreis der bewidmeten Klöster und geistlichen Institutionen veränderte ${ }^{76}$. In der Memoria sichtbar werdende Schenkungsbeziehungen legen in diesen Fällen ein individuelles Netzwerk persönlicher Beziehungen offen, das sich von Adeligen zu Adeligen und nicht von Adelsgeschlecht zu Adelsgeschlecht veränderte.

Eine weitere mögliche Motivation einer Klostergründung, die zugleich überleitet zu einer wesentlichen Funktion, sei abschließend erwähnt. Dass die Neugründungen des endenden 11. und des 12. Jahrhunderts so im Raum positioniert wurden, dass sie Herrschaftsraum sicherten oder abgrenzten bzw. in ungeklärten Bereichen Ansprüche im Raum markierten, ist allseits bekannt. Auch Bronnbach wurde zwischen Mainzer und Würzburger Einflusszonen errichtet. Klostergründungen hatten somit auch eine eminente Bedeutung für das adelige Herrschaftsgefüge; sie verklammerten Räume; anders als Burgen waren sie durch ihre sakrale Fundierung resistenter gegen Veränderungen. Ihnen kam auch im Inneren des personalen Gefüges zwischen einem Herrn, seinem edelfreien und ministerialischen Gefolge eine besondere Aufgabe zu. Das Gefolge konnte sich beim Kloster bestat-

74 Zur späteren, habsburgischen Geschichte Ottmarsheims: René Bornert, Les monastères d'Alsace, Tom. III. Monastères et prieurés. Abbayes et Monastères de Bénédictines des origines à la révolution française, Strasbourg 2010, S. 486-524.

75 Jochen Luckнавdт, Grabmal und Totengedächtnis Heinrichs des Löwen, in: Heinrich der Löwe und seine Zeit. Herrschaft und Repräsentation der Welfen 1125-1235. Katalog der Ausstellung Braunschweig 1995, Bd. 2: Essays, hg. von Jochen Luck HARDT/Franz NieHoff, München 1995, S. 283-291.

76 Jürgen Dendorfer, Verwandte, Freunde und Getreue - Adelige Gruppen in der klösterlichen Memoria des 12. Jahrhunderts in Bayern, in: Adelige - Stifter - Mönche (wie Anm. 66) S. 63-105. 
ten lassen, in dem auch der adelige Herr lag, es schenkte ebenfalls zum Seelenheil an dieses.

Nach Otto Gerhard Oexle umfasst das „adelige Haus“ eine Vielzahl „dinglicher und personaler Verhältnisse ...: die räumliche Behausung, den Wohnsitz, das Vermögen und vor allem die zum Haus gehörenden Personen“, während das „Adelsgeschlecht“ dessen historische Tiefendimension, die „Lebende und Tote vereinigende Abstammungsgemeinschaft" ausmacht ${ }^{77}$. Unter dem adeligen Haus ist somit abgesehen von der Dynastie auch eine adelige domus, wie sie etwa in der Historia Welforum beschrieben wird, zu verstehen: eine geordnetes „Haus“ mit Hofämtern, in das sich Hochgestellte und Niedere in die familia einfügen ${ }^{78}$. Thomas Zotz hat vom Beispiel St. Peter auf dem Schwarzwald ausgehend dafür plädiert, den Hausklosterbegriff zu erweitern und ihn so zu verstehen, dass darin auch „die um die Gefolgsleute erweiterte domus“ eingeschlossen sei ${ }^{79}$. In diesem Sinn kann man in der Tat weiterhin von „Hausklöstern“ sprechen, wenn man auf die integrierende Funktion der Klosterstiftungen für den Herrschaftsverband blickt. Das „Adelshaus“ verstanden als Adelsgeschlecht bildete sich aber nicht zwangsläufig in der klösterlichen Memoria aus. Bei großen Adelsfamilien, die mehrere Klöster gründeten, ließe sich zumindest über ein Modell nachdenken, das den räumlichen Wechsel der Grablegen nicht als Defizit im Sinne eines „Hausklosters“ sieht, sondern darin das Streben um die Einbindung und sakrale Verankerung verschiedener Herrschaftsbereiche erkennen lässt. Das Beispiel der Staufer mag dies noch einmal belegen - von Lorch über St. Walburg bis nach Ebrach dienten die Grablegen der frühen Staufer sicher auch zur sakralen Stabilisierung verschiedener Herrschaftskerne, vom schwäbischen Kernland, über das Elsass bis nach Franken findet sich freies und ministerialisches Gefolge um das jeweilige Kloster ${ }^{80}$. Diese Klostergründungen sind somit Ausdruck neuer herrschaftlicher Schwerpunktsetzungen

77 Otto Gerhard Oexle, Adeliges Selbstverständnis und seine Verknüpfung mit dem liturgischen Gedenken - das Beispiel der Welfen, in: ZGO 134 (1986) S. 47-75, hier S. 47 f.; dazu Werner Hechberger, Haus und Geschlecht. Anmerkungen zu den Welfen des 12. Jahrhunderts, in: ZWLG 66 (2007) S. 47-61.

78 Historia Welforum cum continuatione Staingadensi, in: Quellen zur Geschichte der Welfen und die Chronik Burchards von Ursberg, hg. und übersetzt von Matthias BECHER, unter Mitarbeit von Florian Hartmann und Alheydis Plassmann (Ausgewählte Quellen zur deutschen Geschichte des Mittelalters - Freiherr-vom-Stein-Gedächtnisausgabe, Bd.18b), Darmstadt 2007, S. 34-91, hier c. 1, S. 36: Domum quoque suam regio more ordinaverant, ita ut quaeque officia curiae (id est ministeria dapiferi, pincernae, marscalci, camerarii, signiferi) per comites vel eis aequipollentes regerentur. Praefecerant etiam familiae suae tam maiori quam minori unum de maioribus curiae, quem nominabant advocatum, qui vice sua pro omnibus suis staret coram regibus sen ducibus vel aliis indicibus et in quacumque causa vel querimonia pro eis responderet.

79 Zotz (wie Anm. 61) S. 76 f.

${ }^{80}$ Gerhard Luвich, Territorien-, Kloster- und Bistumspolitik in einer Gesellschaft im Wandel. Zur politischen Komponente des Herrschaftsaufbaus der Staufer vor 1138, in: DeNDORFer/Seibert, Grafen (wie Anm. 44) S. 179-211. 
Herzog Friedrichs I., König Konrads oder Herzog Friedrichs II. und nicht der Staufer.

In den vorhergehenden, in diesem Rahmen eher kursorischen Bemerkungen sollten einige Überlegungen dazu vorgestellt werden, welche Deutungsperspektiven sich ergeben, wenn adelige Gründungen des Hochmittelalters nicht a priori als auf Generationen hin berechnete „Hausklöster“ betrachtet werden. Natürlich gibt es auch „Hausklöster“ im gewohnten Sinne, St. Peter auf dem Schwarzwald könnte ein solches sein, ihm wären andere an die Seite zu stellen. Gerade eine umsichtige Differenzierung aber erlaubt es, diesen besonderen Typ herauszustellen und danach zu fragen, ab wann die Gründung solcher auf ein Geschlecht bezogener Klöster zum festen, adeligen Handlungsmuster wurde. Der Blick auf noch offene Gründungssituationen ermöglicht weiterführende Aussagen über Motive und Strategien der Akteure.

Behandelt habe ich adelige Klostergründungen vor und nach 1100 , etwa in einem Zeitraum von 1050 bis 1150, mit einem Schwerpunkt auf südwestdeutschen Beispielen. Unausgesprochen stand dabei das benediktinische Kloster Hirsauer oder St. Blasianer Prägung, das für die Thesenbildung zum Wandel des Adelsgeschlechts im Hochmittelalter wichtig war, im Zentrum. In der zweiten Hälfte des 12. Jahrhunderts ist dies nicht mehr das maßgebliche Modell, Frauenklöster mit ihren deutlicher nachweisbaren Verflechtungen zwischen der Stifterfamilie und dem Konvent scheinen nun bedeutender für die adelige Memoria zu werden, die Zahl adeliger Klostergründungen selbst geht stark zurück. Diese Entwicklung kann ich hier ebenso nur andeuten wie die changierende Anziehungskraft unterschiedlicher spiritueller Modelle für adelige Stifter zu erörtern bliebe, von den Chorherrenreformen bis hin zu den Zisterziensern, die vor allem für das edelfreie Milieu attraktiv gewesen zu sein scheinen. Das von Beringer von Gamburg und seinen Genossen um das Jahr 1153 gegründete Kloster Bronnbach mag am Ende noch einmal dafür stehen. 